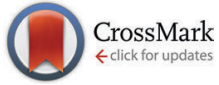

Cite this: Phys. Chem. Chem. Phys., 2015, 17, 15928

Received 5th April 2015, Accepted 18th May 2015

DOI: $10.1039 / c 5 c p 01979 f$

www.rsc.org/pccp

\title{
Nanodusty plasma chemistry: a mechanistic and variational transition state theory study of the initial steps of silyl anion-silane and silylene anion-silane polymerization reactions $\dagger$
}

\author{
Junwei Lucas Bao, Prasenjit Seal and Donald G. Truhlar*
}

\begin{abstract}
The growth of nanodusty particles, which is critical in plasma chemistry, physics, and engineering. The aim of the present work is to understand the detailed reaction mechanisms of early steps in this growth. The polymerization of neutral silane with the silylene or silyl anion, which eliminates molecular hydrogen with the formation of their higher homologues, governs the silicon hydride clustering in nanodusty plasma chemistry. The detailed mechanisms of these important polymerization reactions in terms of elementary reactions have not been proposed yet. In the present work, we investigated the initial steps of these polymerization reactions, i.e., the $\mathrm{SiH}_{4}+\mathrm{Si}_{2} \mathrm{H}_{4}{ }^{-} / \mathrm{Si}_{2} \mathrm{H}_{5}{ }^{-}$reactions, and we propose a three-step mechanism, which is also applicable to the following polymerization steps. CM5 charges of all the silicon-containing species were computed in order to analyze the character of the species in the proposed reaction mechanisms. We also calculated thermal rate constant of each step using multi-structural canonical variational transition state theory (MS-CVT) with the small-curvature tunneling (SCT) approximation, based on the minimum energy path computed using M08-HX/MG3S electronic structure method
\end{abstract}

\section{Introduction}

Pioneering research work on plasmas is quite old, ${ }^{1}$ and research interest continues due to their increasing application in industry, such as fabrication of chips and other microelectronic devices. Dusty plasmas (sometimes called complex plasmas) contain dispersed particulates, which may have various sizes. Methodologies for synthesizing and growing nanosized particles are a major subject of research in material sciences, and plasmas are promising media for such synthesis. Silane-based reactive plasmas $^{2}$ are widely used in the semiconductor industry, and understanding the mechanisms of growth of dust particles with sizes ranging from a few nanometers to several tens of microns is of great importance in nanodusty plasma chemistry, plasma physics, and engineering, for synthesis of desired nanoparticles, for avoiding the production of undesired ones (contaminants), and for equipment design.

In reactive plasmas, beginning with the formation of subnanometer-sized precursor particles nucleated as a result

Department of Chemistry, Chemical Theory Center, and Supercomputing Institute, University of Minnesota, Minneapolis, Minnesota 55455-043, USA.

E-mail: truhlar@umn.edu

$\dagger$ Electronic supplementary information (ESI) available: Cartesian coordinates of M08-HX/MG3S optimized structures of all the species in the proposed reaction mechanisms; thermodynamic and quasithermodynamic quantities at various temperatures. See DOI: 10.1039/c5cp01979f of heterogeneous or homogeneous processes, the generated nanodusty particles will eventually become micron-sized dust by slowly accreting ionic or neutral monomers. ${ }^{3-5}$ Bhandarkar $^{6-8}$ and Gallagher ${ }^{9}$ utilized steady-state homogenous nucleation models to describe the initial stages of the growth of dust particles in pure silane plasma; in these models $\mathrm{SiH}_{3}{ }^{-}$or neutral $\mathrm{SiH}_{m}{ }^{10-12}$ (such as $\mathrm{SiH}_{2}$ radical, $\mathrm{SiH}_{4}$ molecule etc.) triggers the particle growth process, which polymerizes the monomers to silicon hydride clusters with a large number of silicon atoms.

Silicon hydride clustering in plasmas is governed by reactions between cations, anions, and neutrals. ${ }^{7,8}$ Anion-neutral reactions, involving negative ions trapped by the ambipolar potential in the plasma, are an especially important route for generating nanodusty powder in silane-based chemically active plasmas; these reactions can increase the average residence time of the clusters ${ }^{13}$ and enable their growth to a critical size. By using time-resolved mass spectrometry, Hollenstein et al. concluded $^{14}$ that the anionic pathway is the chief route for generating nanosized particles in silane plasmas. Howling and coworkers ${ }^{15}$ also experimentally observed the existence of anionic species with various sizes ranging from monosilicon anions to nanometer clusters.

Bhandarkar and co-workers ${ }^{8}$ studied the following two classes of anion-neutral polymerization reactions:

1. Silylene anion-neutral silane reactions:

$$
\mathrm{Si}_{n+1} \mathrm{H}_{2 n+2}{ }^{-}+\mathrm{SiH}_{4} \rightarrow \mathrm{Si}_{n+2} \mathrm{H}_{2 n+4}{ }^{-}+\mathrm{H}_{2}
$$


2. Silyl anion-neutral silane reactions:

$$
\mathrm{Si}_{n} \mathrm{H}_{2 n+1}{ }^{-}+\mathrm{SiH}_{4} \rightarrow \mathrm{Si}_{n+1} \mathrm{H}_{2 n+3}{ }^{-}+\mathrm{H}_{2} \text {. }
$$

Both these classes of polymerization reactions eliminate molecular hydrogen and result in higher-order homologs of silylene anion or silyl anion clusters. The first step of silylene anionneutral silane polymerization is

$$
\mathrm{Si}_{2} \mathrm{H}_{4}{ }^{-}+\mathrm{SiH}_{4} \rightarrow \mathrm{Si}_{3} \mathrm{H}_{6}{ }^{-}+\mathrm{H}_{2}
$$

and the first step of silyl anion-neutral silane polymerization is

$$
\mathrm{Si}_{2} \mathrm{H}_{5}{ }^{-}+\mathrm{SiH}_{4} \rightarrow \mathrm{Si}_{3} \mathrm{H}_{7}{ }^{-}+\mathrm{H}_{2}
$$

The objective of the present article is to elucidate the mechanisms of these reactions at the molecular level and to calculate their rates. We propose a three-reaction mechanism for both (R1) and (R2), and we study the kinetics of these reactions by using KohnSham density functional theory and direct dynamics variational transition state theory calculations.

\section{Computational details}

Geometry optimizations are carried out with the $\mathrm{M} 08-\mathrm{HX}^{16}$ exchange-correlation functional and the $\mathrm{MG}^{17} \mathrm{~S}^{17}$ basis set, and we perform frequency analysis in order to characterize the stationary points as either equilibrium structures (no imaginary frequencies) or transition structures with one imaginary frequency. The MG3S basis set is an all-electron basis set that for silicon and hydrogen atoms is equivalent to Pople's triple-zeta splitvalence basis with diffuse functions added on silicon atoms and polarization functions on both silicon and hydrogen atoms, in particular $6-311+\mathrm{G}(3 \mathrm{~d} 2 \mathrm{f}, 2 \mathrm{p}){ }^{18-20}$ The global-hybrid meta-GGA density functional M08-HX is chosen based on its superb performances for main-group reaction barrier heights, reaction energies, and thermochemistry. ${ }^{21}$ The numerical integrations were performed using a grid with 99 radial shells around each atom and 974 Lebedev angular points $^{22}$ in each shell. All the electronic calculations were carried out with locally modified Gaussian 09 software. ${ }^{23,24}$

In order to help us understand the proposed reaction mechanisms, CM5 charges $^{25}$ were calculated using the code package CM5PAC. ${ }^{26}$ The CM5 model involves a parametrized mapping of Hirshfeld charges, ${ }^{27}$ where the parameters were determined $^{25}$ to reproduce accurate dipole moments.

Rate constants were calculated by multi-structural canonical variational transition state theory ${ }^{28-31}$ with small-curvature tunneling $^{32}$ (MS-CVT/SCT) by using the following equation:

$$
k^{\mathrm{MS}-\mathrm{CVT} / \mathrm{SCT}}=F_{\mathrm{act}}^{\mathrm{MS}-\mathrm{T}} k^{\mathrm{CVT} / \mathrm{SCT}}
$$

where $k^{\mathrm{MS}-\mathrm{CVT} / \mathrm{SCT}}$ and $k^{\mathrm{CVT} / \mathrm{SCT}}$ are respectively the MS-CVT/ $\mathrm{SCT}^{28}$ and single-structure CVT/SCT ${ }^{29-31}$ rate constants, and $F_{\text {act }}^{\text {MS-T }}$ is the multi-structural torsional anharmonicity factor of activation computed as:

$$
F_{\mathrm{act}}^{\mathrm{MS}-\mathrm{T}}=\frac{Q_{\mathrm{TS}}^{\mathrm{MS}-\mathrm{T}} / Q_{\mathrm{TS}}^{\mathrm{SS}-\mathrm{HO}}}{\left(Q_{\mathrm{R} 1}^{\mathrm{MS}-\mathrm{T}} / Q_{\mathrm{R} 1}^{\mathrm{SS}-\mathrm{HO}}\right) \cdot\left(Q_{\mathrm{R} 2}^{\mathrm{MS}-\mathrm{T}} / Q_{\mathrm{R} 2}^{\mathrm{SS}-\mathrm{HO}}\right)}
$$

where $Q_{\mathrm{X}}^{\mathrm{MS}-\mathrm{T}}$ is the multi-structural rovibrational partition function with torsional anharmonicity for the transition state $(\mathrm{X}=\mathrm{TS})$ or the reactant $(\mathrm{X}=\mathrm{R})$; and $Q_{\mathrm{X}}^{\mathrm{SS}-\mathrm{HO}}$ is the single-structural rovibrational partition function based on rigid-rotor and quasiharmonic oscillator approximations. The multi-structural partition functions with torsional anharmonicity are computed based on coupled torsional barriers $^{33}$ (the MS-T coupled method) using the MSTor program. ${ }^{34}$ The quasiharmonic approximation involves using the harmonic oscillator expressions for the partition functions but with frequencies empirically scaled to give more accurate zero point energies.

The CVT/SCT thermal rate constants were computed by M08-HX/MG3S with minimum-energy paths (MEPs) calculated for the range from $s=-2.0$ to $+2.0 \mathrm{bohr}$, where $s$ is the signed distance along the MEP. The generalized normal mode analyses were performed using non-redundant curvilinear coordinates ${ }^{35,36}$ with a scaling factor of $0.973 .{ }^{37}$ All the direct dynamics calculations were performed with the Polyrate ${ }^{38}$ and Gaussrate ${ }^{39}$ programs.

Energetic results will be reported as relative energies, relative to the reactants of (R1) and (R2): potential energies, $V$, thermodynamic energies, $\Delta U_{T}^{\circ}$, at temperature $T$, and standard-state enthalpies, $\Delta H_{T}^{\circ}$, and standard-state Gibbs free energies, $\Delta G_{T}^{\circ}$, also at a given temperature. Potential energies contain neither zero point energy (ZPE) nor thermal electronic-vibrationaltranslational-rotational energies. All partition functions include electronic degeneracies, and vibrational anharmonicity and rotations are included by the MS-T coupled method. Potential energies, enthalpies, and free energies of transition structures relative to reactants are called classical barrier heights, enthalpies of activation, and free energies of activation; the latter two quantities are quasithermodynamic variables since the transition structures exclude the reaction coordinate. As usual, the standard state for gaseous species is taken as an ideal gas at 1 bar partial pressure. Thermodynamic and quasithermodynamic quantities are given for $T=298 \mathrm{~K}$ in the paper, and results for $T=0,400,500$, $600,700,800,900,1000$, and $1500 \mathrm{~K}$ are given in the ESI. $\dagger$ At $0 \mathrm{~K}$, the standard-state thermodynamic energy and standard-state enthalpy are equal to the standard-state free energy, and all three reduce to the summation of potential energy and zero-point vibrational energy.

\section{Results and discussions}

\subsection{Proposed mechanisms and potential energetics for silane-silylene/silyl anion polymerization reactions}

In order to propose a reasonable reaction pathway, both the thermodynamic and kinetic feasibilities have been taken into consideration. In the present case there is little experimental information to guide the selection of a pathway, so in order to find a chemically reasonable mechanism we mainly relied on exploration of the thermodynamic and kinetic requirements for producing possible intermediates. The mechanism we propose is given in the next two paragraphs. The chemical reasonableness of our proposed reaction mechanism is illustrated by CM5 charge calculations, which will be discussed in Section 3.3. 
Table 1 Steps in the mechanisms

\begin{tabular}{lll}
\hline Reaction & Step & Chemical equation \\
\hline 1 & 1 & $\mathrm{Si}_{2} \mathrm{H}_{4}{ }^{-}+\mathrm{SiH}_{4} \rightarrow \mathrm{SiH}_{3} \mathrm{SiHSiH}_{3}{ }^{-}+\mathrm{H}$ \\
1 & 2 & $\mathrm{SiH}_{3} \mathrm{SiHSiH}_{3}{ }^{-}+\mathrm{H} \rightarrow \mathrm{SiH}_{2} \mathrm{SiHSiH}_{3}{ }^{-}+\mathrm{H}_{2}$ \\
1 & 3 & $\mathrm{SiH}_{2} \mathrm{SiHSiH}_{3}{ }^{-} \rightarrow \mathrm{SiHSiH}_{2} \mathrm{SiH}_{3}{ }^{-}$ \\
2 & 1 & $\mathrm{Si}_{2} \mathrm{H}_{5}{ }^{-}+\mathrm{SiH}_{4} \rightarrow \mathrm{Si}_{2} \mathrm{H}_{6}+\mathrm{SiH}_{3}{ }^{-}$ \\
2 & 2 & $\mathrm{Si}_{2} \mathrm{H}_{6}+\mathrm{SiH}_{3}{ }^{-} \rightarrow \mathrm{SiH}_{2} \mathrm{SiH}_{2} \mathrm{SiH}_{3}{ }^{-}+\mathrm{H}_{2}$ \\
2 & 3 & $\mathrm{SiH}_{2} \mathrm{SiH}_{2} \mathrm{SiH}_{3}{ }^{-} \rightarrow \mathrm{SiH}_{3} \mathrm{SiHSiH}_{3}{ }^{-}$ \\
\hline
\end{tabular}

For the silane-silylene anion reaction (R1 with $n=1$ ), the first step is the nucleophilic attack of the disilan-1,1-diyl anion $\left(\mathrm{Si}_{2} \mathrm{H}_{4}{ }^{-}\right.$, doublet state) on $\mathrm{SiH}_{4}$ to produce trisilan-2-yl anion $\left(\mathrm{Si}_{3} \mathrm{H}_{7}{ }^{-}\right.$, singlet state) and hydrogen radical. The second step is the abstraction of $\mathrm{H}$ atom from the terminal silyl $\left(-\mathrm{SiH}_{3}\right)$ group of trisilan-2-yl anion by $\mathrm{H}$ radical to produce trisilan-1,2-diyl anion $\left(\mathrm{Si}_{3} \mathrm{H}_{6}{ }^{-}\right.$, doublet state) and molecular $\mathrm{H}_{2}$. The final step is an intramolecular 1,2 hydrogen transfer from one isomer of $\mathrm{Si}_{3} \mathrm{H}_{6}{ }^{-}$, i.e., trisilan-1,2-diyl anion, to another one, which is the final product, the trisilan-1,1-diyl anion (singlet state) along with the $\mathrm{H}_{2}$ released in the second step. Total charge is conserved at every step, and all steps are spin-allowed. These reactions are summarized in Table 1, and the potential energy profile for the mechanistic pathway just specified is given in Fig. 1. The classical barrier heights for the first, second and third step are calculated to be $21.1,1.1$, and $23.0 \mathrm{kcal} \mathrm{mol}^{-1}$, respectively.

For silane-silyl anion reaction ( $\mathrm{R} 2$ with $n=2$ ), the reaction mechanism starts with the abstraction of Hydrogen atom from $\mathrm{SiH}_{4}$ by disilan-1-yl anion $\left(\mathrm{Si}_{2} \mathrm{H}_{5}{ }^{-}\right.$, singlet state) to form disilane $\left(\mathrm{Si}_{2} \mathrm{H}_{6}\right)$ and silyl anion $\left(\mathrm{SiH}_{3}{ }^{-}\right.$, singlet state). The second step is the formation of molecular $\mathrm{H}_{2}$ by the reaction of $\mathrm{Si}_{2} \mathrm{H}_{6}$ and $\mathrm{SiH}_{3}{ }^{-}$yielding trisilan-1-yl anion $\left(\mathrm{Si}_{3} \mathrm{H}_{7}{ }^{-}\right.$, singlet state). The terminally negatively charged (formal charge) trisilan-1-yl anion could react with another $\mathrm{SiH}_{4}$ molecule and thus generate higher order homologues. In order to get an isomer of $\mathrm{Si}_{3} \mathrm{H}_{7}{ }^{-}$with lower energy, an intramolecular 1,2 hydrogen transfer from trisilan-1-yl anion to trisilan-2-yl anion (singlet state) could further occur.

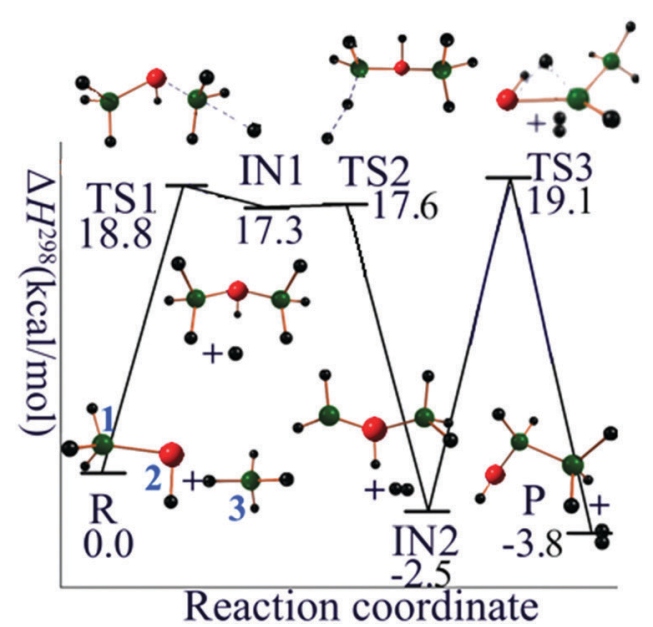

Fig. 1 Reaction mechanism profile for $\mathrm{SiH}_{4}+\mathrm{Si}_{2} \mathrm{H}_{4}{ }^{-}$. Green balls are silicon atoms, and small black balls are hydrogen atoms. The silicon atoms in red carry one negative formal charge.

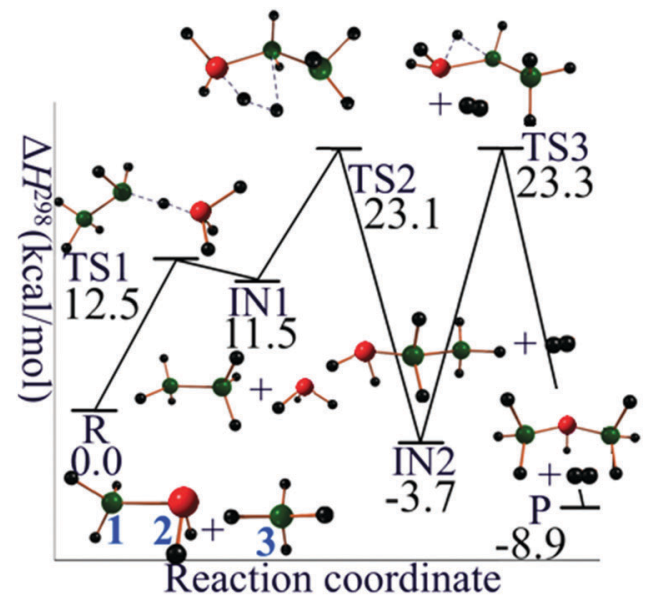

Fig. 2 Reaction mechanism profile for $\mathrm{SiH}_{4}+\mathrm{Si}_{2} \mathrm{H}_{5}{ }^{-}$. Green balls are silicon atoms, and small black balls are hydrogen atoms. The silicon atoms in red carry one negative formal charge.

The potential energy profile for the mechanistic pathway of reaction $\mathrm{R} 2$ is shown in Fig. 2. The classical barrier heights for the first, second, and third step are calculated to be 15.0, 13.0, and $27.4 \mathrm{kcal} \mathrm{mol}{ }^{-1}$, respectively.

\subsection{Thermodynamic and quasithermodynamic quantities}

The M08-HX/MG3S calculated potential energy change for the overall reaction, $\mathrm{Si}_{2} \mathrm{H}_{4}{ }^{-}+\mathrm{SiH}_{4} \rightarrow \mathrm{Si}_{3} \mathrm{H}_{6}{ }^{-}+\mathrm{H}_{2}$, is $-3.1 \mathrm{kcal} \mathrm{mol}^{-1}$, and the reaction enthalpy at $298 \mathrm{~K}$ is $-3.8 \mathrm{kcal} \mathrm{mol}^{-1}$. The thermodynamic and quasithermodynamic functions are given for $T=298 \mathrm{~K}$ in Table 2 and for other temperatures in ESI. $\dagger$

The M08-HX/MG3S calculated potential energy of reaction for the overall reaction, $\mathrm{Si}_{2} \mathrm{H}_{5}{ }^{-}+\mathrm{SiH}_{4} \rightarrow \mathrm{Si}_{3} \mathrm{H}_{7}{ }^{-}+\mathrm{H}_{2}$, is

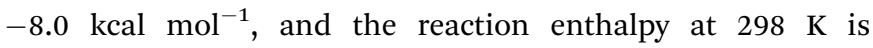
$-8.9 \mathrm{kcal} \mathrm{mol}^{-1}$. The thermodynamic and quasithermodynamic functions are given for $T=298 \mathrm{~K}$ in Table 3 and for other temperatures in ESI. $\dagger$

\subsection{CM5 charge analysis of reaction mechanisms}

In order to further understand the proposed reaction mechanism, we computed partial atomic charges on the species in the mechanism. We did this by employing the CM5 charge model to extract partial atomic charges for all silicon-containing species from the Slater determinants employed in the KohnSham density functional calculations. We report the charges in Fig. 3 by taking the charge unit as the charge on a proton; the labels of the silicon atoms in Fig. 3 are consistent with the labels in Fig. 1 and 2 (the numbers 1, 2, 3 marked in blue). Notice that in some cases the labels of the two symmetric silicon atoms are interchangeable (such as $\mathrm{Si}-1$ and $\mathrm{Si}-3$ in intermediate 1 of $\mathrm{R} 1, \mathrm{Si}-1$ and $\mathrm{Si}-2$ in disilane of R2).

For reaction $\mathrm{Si}_{2} \mathrm{H}_{4}{ }^{-}+\mathrm{SiH}_{4} \rightarrow \mathrm{Si}_{3} \mathrm{H}_{6}{ }^{-}+\mathrm{H}_{2}$, as we can see from Fig. 3(a) that the charges on $\mathrm{Si}-3$ remain almost the same after the first step, while Si-1 and Si-2 have changed considerably. In the starting reactant, $\mathrm{SiH}_{3} \mathrm{SiH}^{-}, \mathrm{Si}-2$ possesses the most negative charge $(-0.52)$, which is consistent with the formal charge -1 assigned on this silicon in the Lewis structure. In the 
Table 2 Thermodynamic and quasithermodynamic functions at $T=298 \mathrm{~K}$ for reaction R1. Enthalpy, Gibbs free energy, and thermodynamic energy are reported with respect to reactants $\left(\mathrm{SiH}_{4}+\mathrm{Si}_{2} \mathrm{H}_{4}{ }^{-}\right)$

\begin{tabular}{lcrr}
\hline Species & $\Delta H_{298}^{\circ}\left(\mathrm{kcal} \mathrm{mol}^{-1}\right)$ & $\Delta G_{298}^{\circ}\left(\mathrm{kcal} \mathrm{mol}^{-1}\right)$ & $\Delta U_{298}^{\circ}\left(\mathrm{kcal} \mathrm{mol}^{-1}\right)$ \\
\hline $\mathrm{SiH}_{4}+\mathrm{Si}_{2} \mathrm{H}_{4}{ }^{-}$ & 0.0 & 0.0 & 0.0 \\
$\mathrm{TS} 1$ & 18.8 & 27.0 & 19.4 \\
$\mathrm{SiH}_{3} \mathrm{SiHSiH}_{3}{ }^{-}+\mathrm{H}$ & 17.3 & 19.1 & 17.3 \\
$\mathrm{TS} 2$ & 17.6 & 25.2 & 18.1 \\
$\mathrm{SiH}_{2} \mathrm{SiHSiH}_{3}{ }^{-}+\mathrm{H}_{2}$ & -2.5 & -2.1 & -2.5 \\
$\mathrm{TS} 3+\mathrm{H}_{2}$ & 19.1 & 19.9 & 19.1 \\
$\mathrm{SiHSiH}_{2} \mathrm{SiH}_{3}{ }^{-}+\mathrm{H}_{2}$ & -3.8 & -3.5 & -3.8
\end{tabular}

Table 3 Thermodynamic and quasithermodynamic functions at $T=298 \mathrm{~K}$ for reaction R2. Enthalpy, Gibbs free energy and thermodynamic energy are reported with respect to reactants $\left(\mathrm{SiH}_{4}+\mathrm{Si}_{2} \mathrm{H}_{5}{ }^{-}\right)$

\begin{tabular}{lccr}
\hline Species & $\Delta H_{298}^{\circ}\left(\mathrm{kcal} \mathrm{mol}^{-1}\right)$ & $\Delta G_{298}^{\circ}\left(\mathrm{kcal} \mathrm{mol}^{-1}\right)$ & $\Delta U_{298}^{\circ}\left(\mathrm{kcal} \mathrm{mol}^{-1}\right)$ \\
\hline $\mathrm{SiH}_{4}+\mathrm{Si}_{2} \mathrm{H}_{5}{ }^{-}$ & 0.0 & 0.0 & 0.0 \\
$\mathrm{TS} 1$ & 12.5 & 19.5 & 13.1 \\
$\mathrm{Si}_{2} \mathrm{H}_{6}+\mathrm{SiH}_{3}{ }^{-}$ & 11.5 & 11.0 & 11.5 \\
$\mathrm{TS}$ & 23.1 & 34.0 & 23.7 \\
$\mathrm{SiH}_{2} \mathrm{SiH}_{2} \mathrm{SiH}_{3}{ }^{-}+\mathrm{H}_{2}$ & -3.7 & -3.8 & -3.7 \\
$\mathrm{TS}+\mathrm{H}_{2}$ & 23.3 & 24.6 & 23.3 \\
$\mathrm{SiH}_{3} \mathrm{SiHSiH}_{3}{ }^{-}+\mathrm{H}_{2}$ & -8.9 & -8.4 & -8.9 \\
\end{tabular}
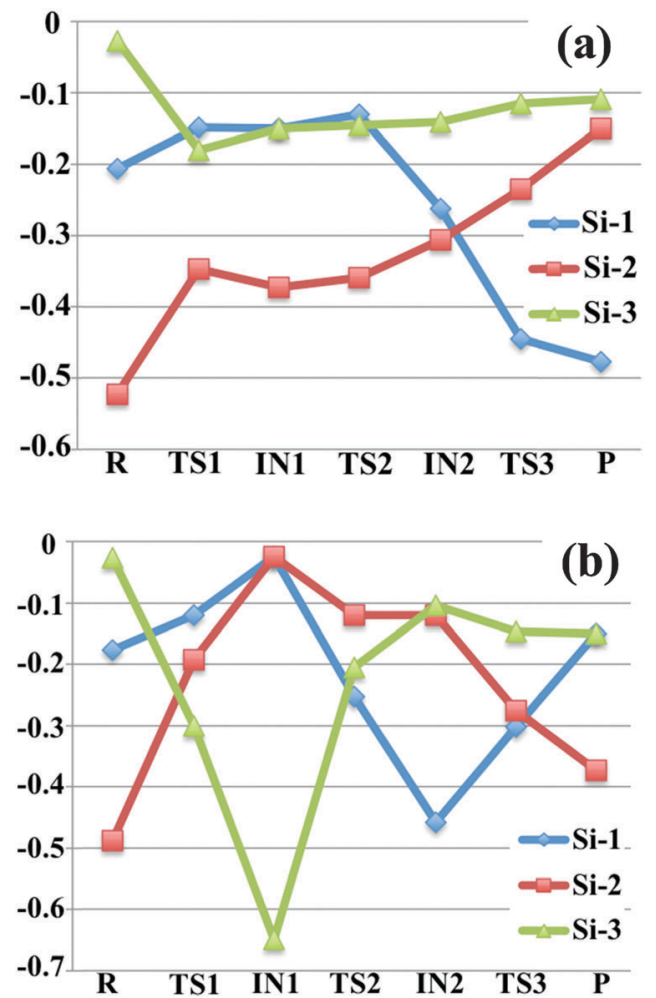

Fig. 3 Computed CM5 charges (in the unit of elementary charge) for all the silicon-containing species in reaction (a) $\mathrm{SiH}_{4}+\mathrm{Si}_{2} \mathrm{H}_{4}^{-}$(b) $\mathrm{SiH}_{4}+$ $\mathrm{Si}_{2} \mathrm{H}_{5}{ }^{-}$. The labels of the silicon atoms are consistent with Fig. 1.

first step of nucleophilic reaction, a portion of the negative charge of silicon-2 is transferred to the silane silicon (Si-3), which raises the charge carried by Si-2 by 0.18 , and lowers the charges on Si-3 by 0.15 in the transition structure TS1. In intermediate $1, \mathrm{SiH}_{3} \mathrm{SiHSiH}_{3}{ }^{-}$, Si-2 still has the most negative charge $(-0.37)$, and the silicon atoms in the two terminal $-\mathrm{SiH}_{3}$ group have the same amount of charge $(-0.15)$ due to the $C_{\mathrm{s}}$ point group symmetry. After the first step, $\mathrm{Si}-3$ remains as part of a $-\mathrm{SiH}_{3}$ group and therefore the CM5 charge on Si-3 is almost unchanged. In the following hydrogen abstraction step, Si-1 loses one bonded hydrogen atom, which lower the charges on Si-1. In the resulting intermediate 2, the amounts of charge carried by Si-1 and Si-2 are very close. After the hydrogen abstraction step, the charges on Si-1 and Si-2 change significantly because of the transfer of the hydrogen from Si-1 to Si-2, which further lower the charge on Si-1 and increases the charges on Si-2. For the overall process, most negative of the charge has been transferred from Si-2 to Si-1, which exchanges the location of the formal charge.

The CM5 charges for $\mathrm{Si}$ atoms in the mechanistic pathway of reaction $\mathrm{Si}_{2} \mathrm{H}_{5}{ }^{-}+\mathrm{SiH}_{4} \rightarrow \mathrm{Si}_{3} \mathrm{H}_{7}^{-}+\mathrm{H}_{2}$ are shown in Fig. 3(b). In the first step, $\mathrm{SiH}_{3} \mathrm{SiH}_{2}{ }^{-}$abstracts a hydrogen atom from the $\mathrm{SiH}_{4}$ molecule, leading to the formation of $\mathrm{SiH}_{3}{ }^{-}$anion, which significantly lowers the charges on Si-3 (from -0.03 to -0.30 in TS1, and to $-0.65{\mathrm{in} \mathrm{SiH}_{3}}^{-}$anion) and increases the charges on Si-1 and Si-2. Then $\mathrm{SiH}_{3}{ }^{-}$attacks disilane to become an $-\mathrm{SiH}_{3}$ group, in which the Si-3 partially transferred its negative charge to $\mathrm{Si}-1$ and $\mathrm{Si}-2$ and remains only slightly negatively charged during the remaining steps. In step 2, which eliminates molecular hydrogen, one of the silicon atoms in disilane gains more negative charges than the other one, which introduces a negative formal charge on the terminal silicon atom. The terminal negative charge could be further transferred to the middle silicon, which lower the energy of the molecule and leads to a thermodynamically more stable isomer.

\subsection{Multi-structural torsional anharmonicity factors}

Multi-structural effects are very important and must be considered in the high temperature range especially for branched silane with long silicon-chain. ${ }^{40}$ Multi-structural anharmonicity and torsional anharmonicity are included in our calculations by the 
Table 4 Multi-structural torsional anharmonicity factors for activation of step $1-3$ in reaction R1 and R2 at various temperatures

\begin{tabular}{|c|c|c|c|c|c|c|}
\hline \multirow[b]{2}{*}{$T / \mathrm{K}$} & \multicolumn{3}{|l|}{$\mathrm{R} 1$} & \multicolumn{3}{|l|}{$\mathrm{R} 2$} \\
\hline & Step 1 & Step 2 & Step 3 & Step 1 & Step 2 & Step 3 \\
\hline 298 & 1.78 & 2.01 & 0.92 & 2.18 & 0.59 & 1.38 \\
\hline 300 & 1.78 & 2.01 & 0.92 & 2.18 & 0.59 & 1.38 \\
\hline 400 & 1.79 & 2.19 & 0.84 & 2.13 & 0.60 & 1.29 \\
\hline 500 & 1.78 & 2.38 & 0.78 & 2.08 & 0.61 & 1.27 \\
\hline 600 & 1.75 & 2.57 & 0.74 & 2.03 & 0.63 & 1.27 \\
\hline 700 & 1.72 & 2.76 & 0.71 & 1.99 & 0.65 & 1.30 \\
\hline 800 & 1.68 & 2.94 & 0.69 & 1.95 & 0.68 & 1.34 \\
\hline 900 & 1.64 & 3.13 & 0.67 & 1.92 & 0.70 & 1.38 \\
\hline 1000 & 1.60 & 3.31 & 0.66 & 1.89 & 0.72 & 1.42 \\
\hline 1500 & 1.44 & 4.13 & 0.61 & 1.78 & 0.84 & 1.65 \\
\hline
\end{tabular}

MS-T coupled method (MS-T(C)). The local periodicities of the $-\mathrm{SiH}_{3}$ groups are assigned as 3 . The calculated multi-structural torsional anharmonicity factors for activation of steps 1-3 in reactions R1 and $\mathrm{R} 2$ at various temperatures are listed in Table 4. Because of the relatively small sizes of the molecules we considered in the current work, the MS-T factors do not significantly deviate from unity. Nevertheless, we find that ignoring such MS-T corrections can still cause an error ranging from $10-75 \%$ in the final predicted thermal rate constants. For instance, at $1500 \mathrm{~K}$, for R1 step 2 of reaction R1, an error of $75 \%$ would be introduced by not multiplying the rate constant with a MS-T factor of 4.13; even at room temperature $(\sim 298 \mathrm{~K})$, in the case of step 2 of reaction R2, the multi-structural rate constant differs from the single-structural rate constant by $69 \%$.

The numbers of distinguishable structures found for $\mathrm{Si}_{2} \mathrm{H}_{4}{ }^{-}$, TS1, $\mathrm{SiH}_{3} \mathrm{SiHSiH}_{3}{ }^{-}$, TS2, $\mathrm{SiH}_{2} \mathrm{SiHSiH}_{3}{ }^{-}$, TS3 and $\mathrm{SiHSiH}_{2} \mathrm{SiH}_{3}{ }^{-}$ are 1, 2, 1, 2, 2, 2, and 2, respectively for R1; and they are 1, 2, 1, 2, 3, 2 and 1 for $\mathrm{Si}_{2} \mathrm{H}_{5}{ }^{-}, \mathrm{TS} 1, \mathrm{Si}_{2} \mathrm{H}_{6}, \mathrm{TS} 2, \mathrm{SiH}_{2} \mathrm{SiH}_{2} \mathrm{SiH}_{3}{ }^{-}$, TS3 and $\mathrm{SiH}_{3} \mathrm{SiHSiH}_{3}{ }^{-}$, respectively for R2. For all species with 2 distinguishable structures, the two structures are a pair of energetically equivalent non-superimposable mirror images. For $\mathrm{SiH}_{2} \mathrm{SiH}_{2} \mathrm{SiH}_{3}{ }^{-}$ anion, there is one $C_{\mathrm{s}}$-symmetry conformer, which is the global minima, and one pair of mirror images, which are $0.76 \mathrm{kcal} \mathrm{mol}^{-1}$ higher in potential energy.

\subsection{Thermal rate constants}

The computed MS-CVT/SCT rate constants of step 1-3 of net reactions R1 and R2 are listed in Table 5 for various temperatures.
Steps 1 and 2 are bimolecular reactions, and step 3 is a unimolecular reaction.

The MS-CVT/SCT rate constants for the forward reactions of steps 1-3 in R1 and R2 are fitted using recently proposed ${ }^{41,42}$ multi-parameter fitting expressions. In particular, for endothermic reactions (steps 1 of R1 and R2)

$$
k=A\left(\frac{T}{300}\right)^{n} \exp \left[-\frac{E\left(T+T_{0}\right)}{R\left(T^{2}+T_{0}^{2}\right)}\right]
$$

where $A, n, E$, and $T_{0}$ are the four fitting parameters, and $R$ is the gas constant $\left(1.9872 \times 10^{-3} \mathrm{kcal} \mathrm{mol}^{-1} \mathrm{~K}^{-1}\right)$. For exothermic reactions (steps 2 and 3 of R1 and R2), a fitting equation that allows a nonzero value of the rate constant at $0 \mathrm{~K}$ is used:

$$
k=A\left(\frac{T+T_{0}}{300}\right)^{n} \exp \left[-\frac{E\left(T+T_{0}\right)}{R\left(T^{2}+T_{0}^{2}\right)}\right]
$$

The fitting parameters are tabulated in Table 6. The fitting parameters for the reverse reactions are in ESI. $\dagger$

The computed CVT recrossing transmission coefficients $\Gamma$ and small-curvature tunneling transmission coefficients $\kappa$ are shown in Table 7.

The variational effects for the systems studied in this work are not particularly significant, the largest variational effect occurs at $298 \mathrm{~K}$ in the last step of R2, with a recrossing transmission coefficient $\Gamma=0.84$ and a generalized transition state (GT) $0.0579 \AA$ away from the saddle point $(s=0)$, which is very close to the conventional transition state. The potential energy $\left(V_{\mathrm{MEP}}\right)$ along the ground-state minimum energy path (MEP) as a function of the reaction coordinate $s$ for step 3 of

Table 6 Fitting parameters for forward reaction rate constants of steps 1-3 in $\mathrm{R} 1$ and $\mathrm{R}^{\mathrm{a}}$

\begin{tabular}{lrlrr}
\hline & \multicolumn{1}{l}{$\ln A$} & $n$ & \multicolumn{1}{l}{$T_{0}$} & \multicolumn{1}{c}{$E$} \\
\hline R1, step 1 & -36.026 & 4.560 & 113.71 & 13.060 \\
R1, step 2 & -26.272 & 2.530 & 334.20 & 0.532 \\
R1, step 3 & 28.201 & 0.667 & 11.56 & 20.190 \\
R2, step 1 & -31.420 & 4.400 & 112.61 & 8.534 \\
R2, step 2 & -41.694 & 5.100 & 158.70 & 6.924 \\
R2, step 3 & 26.161 & 1.060 & 5.00 & 25.910
\end{tabular}

${ }^{a}$ The units of $A$ for steps 1 and 2 are $\mathrm{cm}^{3}$ molecule ${ }^{-1} \mathrm{~s}^{-1}$ and $\mathrm{s}^{-1}$ for step 3; the parameters $T_{0}$ and $E$ are in units of $\mathrm{K}$ and $\mathrm{kcal} \mathrm{mol}^{-1}$ respectively, and $n$ is unitless.

Table 5 MS-CVT/SCT rate constants of step 1-3 in reaction R1 and R2 at various temperatures. (Units: for step 1 and 2 are $\mathrm{cm}^{3} \mathrm{molecule}^{-1} \mathrm{~s}^{-1}$, for step 3

\begin{tabular}{|c|c|c|c|c|c|c|}
\hline \multirow[b]{2}{*}{$T / \mathrm{K}$} & \multicolumn{3}{|l|}{ R1 } & \multicolumn{3}{|l|}{$\mathrm{R} 2$} \\
\hline & Step 1 & Step 2 & Step 3 & Step 1 & Step 2 & Step 3 \\
\hline 298 & $6.17 \times 10^{-28}$ & $1.11 \times 10^{-11}$ & $7.82 \times 10^{-4}$ & $6.22 \times 10^{-22}$ & $5.76 \times 10^{-24}$ & $1.12 \times 10^{-8}$ \\
\hline 300 & $7.65 \times 10^{-28}$ & $1.12 \times 10^{-11}$ & $1.00 \times 10^{-3}$ & $7.23 \times 10^{-22}$ & $6.41 \times 10^{-24}$ & $1.52 \times 10^{-8}$ \\
\hline 400 & $2.86 \times 10^{-24}$ & $1.73 \times 10^{-11}$ & $1.04 \times 10^{1}$ & $2.37 \times 10^{-19}$ & $5.11 \times 10^{-22}$ & $1.48 \times 10^{-3}$ \\
\hline 500 & $5.03 \times 10^{-22}$ & $2.79 \times 10^{-11}$ & $2.30 \times 10^{3}$ & $9.46 \times 10^{-18}$ & $1.03 \times 10^{-20}$ & 1.44 \\
\hline 600 & $1.80 \times 10^{-20}$ & $4.16 \times 10^{-11}$ & $8.90 \times 10^{4}$ & $1.27 \times 10^{-16}$ & $9.22 \times 10^{-20}$ & $1.47 \times 10^{2}$ \\
\hline 700 & $2.57 \times 10^{-19}$ & $5.90 \times 10^{-11}$ & $1.22 \times 10^{6}$ & $8.98 \times 10^{-16}$ & $4.98 \times 10^{-19}$ & $4.08 \times 10^{3}$ \\
\hline 800 & $2.01 \times 10^{-18}$ & $7.24 \times 10^{-11}$ & $8.82 \times 10^{6}$ & $4.16 \times 10^{-15}$ & $1.93 \times 10^{-18}$ & $5.02 \times 10^{4}$ \\
\hline 900 & $1.05 \times 10^{-17}$ & $9.47 \times 10^{-11}$ & $4.07 \times 10^{7}$ & $1.45 \times 10^{-14}$ & $5.89 \times 10^{-18}$ & $3.46 \times 10^{5}$ \\
\hline 1000 & $4.08 \times 10^{-17}$ & $1.21 \times 10^{-10}$ & $1.39 \times 10^{8}$ & $4.07 \times 10^{-14}$ & $1.52 \times 10^{-17}$ & $1.68 \times 10^{6}$ \\
\hline 1500 & $3.17 \times 10^{-15}$ & $3.10 \times 10^{-10}$ & $5.58 \times 10^{9}$ & $1.24 \times 10^{-12}$ & $3.77 \times 10^{-16}$ & $2.08 \times 10^{8}$ \\
\hline
\end{tabular}
is $\mathrm{s}^{-1}$.) 
Table 7 CVT recrossing transmission coefficients and SCT tunneling transmission coefficients for R1 and R2 at various temperatures

\begin{tabular}{|c|c|c|c|c|c|c|c|c|c|c|c|c|}
\hline \multirow[b]{2}{*}{$\mathrm{T} / K$} & \multicolumn{2}{|c|}{ R1-step 1} & \multicolumn{2}{|c|}{ R1-step 2} & \multicolumn{2}{|c|}{ R1-step 3} & \multicolumn{2}{|c|}{ R2-step 1} & \multicolumn{2}{|c|}{ R2-step 2} & \multicolumn{2}{|c|}{ R2-step 3} \\
\hline & $\Gamma$ & $\kappa$ & $\Gamma$ & $\kappa$ & $\Gamma$ & $\kappa$ & $\Gamma$ & $\kappa$ & $\Gamma$ & $\kappa$ & $\Gamma$ & $\kappa$ \\
\hline 298 & 0.98 & 1.87 & 0.90 & 1.43 & 0.98 & 1.65 & 0.97 & 2.48 & 0.99 & 10.21 & 0.84 & 1.61 \\
\hline 300 & 0.98 & 1.85 & 0.90 & 1.42 & 0.99 & 1.64 & 0.97 & 2.45 & 0.99 & 9.82 & 0.84 & 1.60 \\
\hline 400 & 0.98 & 1.39 & 0.97 & 1.22 & 0.99 & 1.52 & 0.98 & 1.71 & 0.99 & 3.23 & 0.88 & 1.39 \\
\hline 500 & 0.98 & 1.23 & 0.97 & 1.14 & 0.99 & 1.26 & 0.98 & 1.42 & 0.98 & 2.05 & 0.91 & 1.23 \\
\hline 600 & 0.98 & 1.14 & 0.97 & 1.09 & 0.99 & 1.17 & 0.98 & 1.28 & 0.98 & 1.63 & 0.92 & 1.15 \\
\hline 700 & 0.97 & 1.10 & 0.98 & 1.07 & 0.99 & 1.12 & 0.98 & 1.20 & 0.98 & 1.42 & 0.93 & 1.11 \\
\hline 800 & 0.97 & 1.07 & 0.99 & 1.05 & 1.00 & 1.08 & 0.98 & 1.15 & 0.98 & 1.30 & 0.94 & 1.08 \\
\hline 900 & 0.97 & 1.05 & 0.98 & 1.04 & 1.00 & 1.06 & 0.98 & 1.12 & 0.98 & 1.23 & 0.96 & 1.06 \\
\hline 1000 & 0.97 & 1.04 & 0.97 & 1.03 & 1.00 & 1.04 & 0.99 & 1.09 & 0.98 & 1.18 & 0.96 & 1.05 \\
\hline 1500 & 0.96 & 1.01 & 0.95 & 1.01 & 0.99 & 1.01 & 0.98 & 1.04 & 0.97 & 1.08 & 0.96 & 1.02 \\
\hline
\end{tabular}
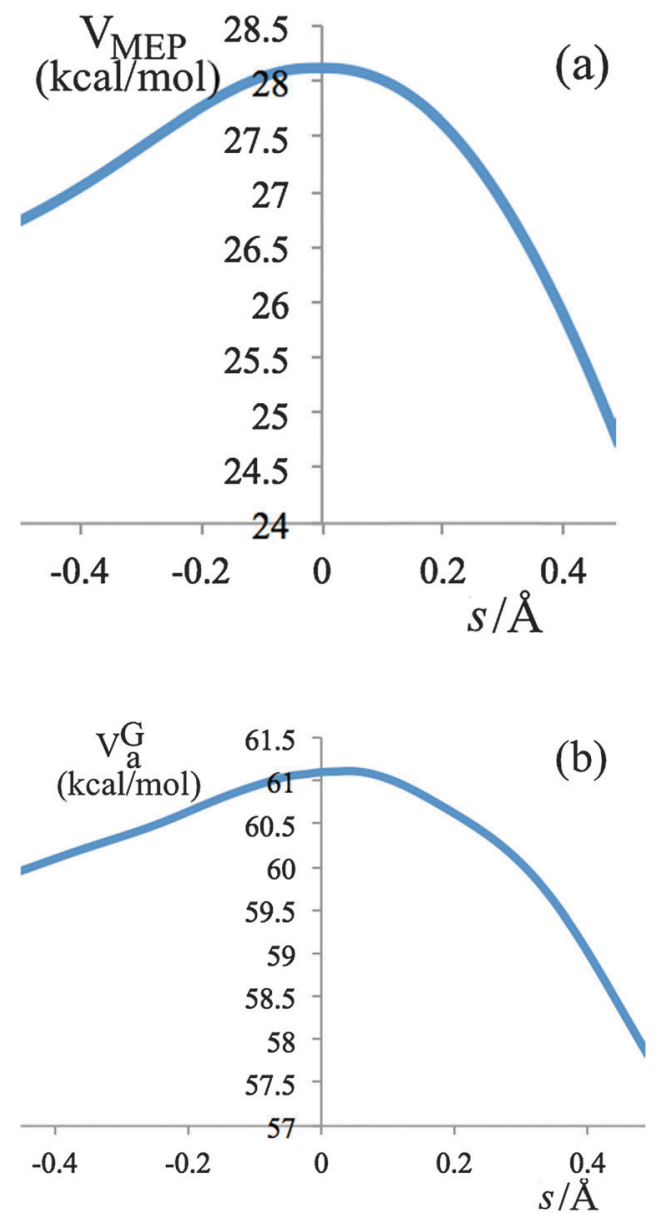

Fig. $4 V_{\text {MEP }}$ and $V_{a}^{G}$ for step 3 of reaction R2 as a function of reaction coordinate $s$, where $s$ is the signed distance along the MEP in isoinertial coordinates scaled to a reduced mass of 1 amu.

reaction R2 is shown in Fig. 4(a); the vibrationally adiabatic ground-state potential energy $\left(V_{\mathrm{a}}^{\mathrm{G}}\right)$, which is the sum of $V_{\mathrm{MEP}}$ and the zero point energies of all the vibrational modes that are orthogonal to the reaction coordinate, is depicted in Fig. 4(b).

Quantum tunneling effect is especially important for light atoms (such as hydrogen) at low temperature range, and the tunneling transmission coefficient gradually converges to unity as the temperature increases. For instance, in the second step

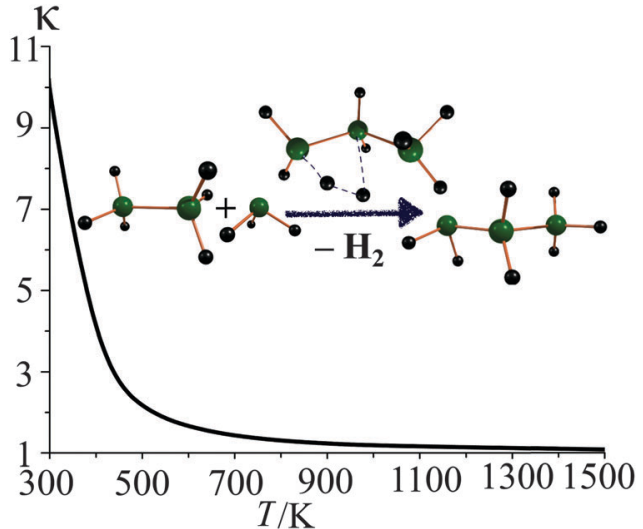

Fig. 5 SCT tunneling transmission coefficients $(\kappa)$ for step 2 of reaction R2 at various temperatures.

of reaction $\mathrm{R} 2$, tunneling at $298 \mathrm{~K}$ increases the thermal rate constant by an order of magnitude. The SCT tunneling transmission factors at various temperatures for this step are depicted in Fig. 5.

\subsection{Activation energies}

Arrhenius activation energies ( $\mathrm{kcal} \mathrm{mol}^{-1}$ ) of steps 1-3 in the reaction pathways of $\mathrm{R} 1$ and $\mathrm{R} 2$ at various temperatures are listed in Table 8. Temperature-dependence of the activation energy is depicted in Fig. 6. Arrhenius activation energies are calculated as the slopes of the Arrhenius plots (plots of $\ln k v$ s. 1/T). ${ }^{43}$ Based on the fitting formulas we adopted in this paper, Arrhenius activation energies can be derived as follows:

$$
E_{\mathrm{a}}= \begin{cases}\frac{E\left(T^{4}+2 T_{0} T^{3}-T_{0}^{2} T^{2}\right)}{\left(T^{2}+T_{0}^{2}\right)^{2}}+n R T & \text { endothermic reaction } \\ \frac{E\left(T^{4}+2 T_{0} T^{3}-T_{0}^{2} T^{2}\right)}{\left(T^{2}+T_{0}^{2}\right)^{2}}+\frac{n R T^{2}}{T+T_{0}} & \text { exothermic reaction }\end{cases}
$$

Arrhenius activation energies are temperature-dependent due to the deviation of Arrhenius plots from straight lines. The differences between $E_{\mathrm{a}}$ at $298 \mathrm{~K}$ and at $1500 \mathrm{~K}$ for step 1-3 of R1 and R2 are, respectively, 9.6, 5.9, 0.8, 9.7, 12.4, $1.8 \mathrm{kcal} \mathrm{mol}^{-1}$. Therefore one would make serious errors if one assumed the

Table 8 Arrhenius activation energies ( $\mathrm{kcal} \mathrm{mol}^{-1}$ ) of step 1-3 in reaction $\mathrm{R} 1$ and R2 at various temperatures

\begin{tabular}{|c|c|c|c|c|c|c|}
\hline \multirow[b]{2}{*}{$T / \mathrm{K}$} & \multicolumn{3}{|l|}{$\mathrm{R} 1$} & \multicolumn{3}{|l|}{$\mathrm{R} 2$} \\
\hline & Step 1 & Step 2 & Step 3 & Step 1 & Step 2 & Step 3 \\
\hline 298 & 18.8 & 0.9 & 21.7 & 13.1 & 9.5 & 27.4 \\
\hline 300 & 18.8 & 0.9 & 21.7 & 13.2 & 9.5 & 27.4 \\
\hline 400 & 20.3 & 1.5 & 21.8 & 14.4 & 11.4 & 27.4 \\
\hline 500 & 21.1 & 2.0 & 21.8 & 15.2 & 12.6 & 27.5 \\
\hline 600 & 21.8 & 2.5 & 21.8 & 15.9 & 13.6 & 27.6 \\
\hline 700 & 22.4 & 3.0 & 21.8 & 16.6 & 14.6 & 27.7 \\
\hline 800 & 23.1 & 3.5 & 21.8 & 17.3 & 15.5 & 27.9 \\
\hline 900 & 23.8 & 4.0 & 21.9 & 18.1 & 16.4 & 28.1 \\
\hline 1000 & 24.5 & 4.4 & 22.0 & 18.8 & 17.3 & 28.3 \\
\hline 1500 & 28.4 & 6.8 & 22.5 & 22.8 & 21.9 & 29.2 \\
\hline
\end{tabular}




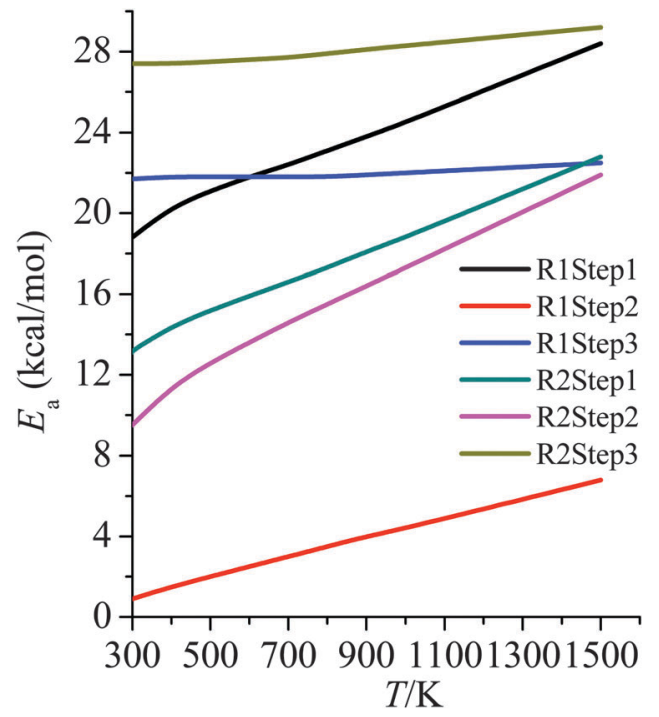

Fig. 6 Activation energies ( $\mathrm{kcal} \mathrm{mol}^{-1}$ ) at various temperatures $(\mathrm{K})$ for all of the steps in R1 and R2.

simple Arrhenius form for the temperature dependences of the rate constants.

\subsection{Additional mechanistic steps}

The rate constants we report here are in the high-pressure limit. In the high-pressure limit, all of the species are fully thermalized (satisfying the Boltzmann distribution), which means that the rates of the collisional energy transfer steps that maintain the equilibrium of reactants and intermediates are faster than the rates of reaction. To include the deviation from the highpressure limit would require adding collisional energy transfer steps to the mechanism and considering the rates of reaction as functions of internal energy distributions. ${ }^{4,45}$

Another mechanistic complication is that in real systems there are other species present. Consequently, $\mathrm{Si}_{3} \mathrm{H}_{7}^{-}$(intermediate 1 of reaction R1) may collide with $\mathrm{SiH}_{4}$ before it collides with an $\mathrm{H}$ atom, and an $\mathrm{H}$ atom may collide with $\mathrm{SiH}_{2}{ }^{-}$before it collides with $\mathrm{Si}_{3} \mathrm{H}_{7}{ }^{-}$. Similarly, all the other intermediates generated during the reaction mechanisms can possibly collide with other species in real chemically active plasma systems. Thus the present work provides the beginning of a quantitative mechanism by presenting forward and reverse rate constants for six elementary steps in the high-pressure limit, but a full mechanism involves many more reactions.

\section{Summary}

The present work is dedicated to understanding the reaction mechanisms in the initial steps of the growth of nanoparticles in nanodusty plasmas. We have proposed three-step mechanisms for the initial steps of the $\mathrm{SiH}_{4}+\mathrm{Si}_{2} \mathrm{H}_{4}{ }^{-}$and $\mathrm{SiH}_{4}+\mathrm{Si}_{2} \mathrm{H}_{5}{ }^{-}$ polymerization reactions. CM5 charges were used to interpret the proposed reaction mechanisms, and rate constants for all the reactions were calculated by multi-structural canonical variational transition state theory with the small-curvature tunneling approximation.

\section{Acknowledgements}

This work is supported by National Science Foundation under award no. CHE11-24752.

\section{References}

1 I. Langmuir, C. G. Found and A. F. Dittmer, Science, 1924, 60, 392-394.

2 S. E. Beck, S. M. Collins and J. F. O'Hanlon, IEEE Trans. Plasma Sci., 1994, 22, 128-135.

3 L. Boufendi and A. Bouchoule, Plasma Sources Sci. Technol., 1994, 3, 262-267.

4 L. Boufendi and A. Bouchoule, Plasma Sources Sci. Technol., 1993, 2, 204-213.

5 L. Boufendi and A. Bouchoule, Plasma Sources Sci. Technol., 2002, 11, A211-A218.

6 U. R. Kortshagen and U. V. Bhandarkar, Phys. Rev. E: Stat. Phys., Plasmas, Fluids, Relat. Interdiscip. Top., 1999, 60, 887-898.

7 U. V. Bhandarkar, M. T. Swihart, S. L. Girshick and U. R. Kortshagen, J. Phys. D: Appl. Phys., 2000, 33, 2731-2746.

8 U. V. Bhandarkar, U. R. Kortshagen and S. L. Girshick, J. Phys. D: Appl. Phys., 2003, 36, 1399-1408.

9 A. Gallagher, Phys. Rev. E: Stat. Phys., Plasmas, Fluids, Relat. Interdiscip. Top., 2000, 62, 2690-2706.

10 Y. Watanabe, M. Shiratani and K. Koga, Phys. Scr., 2001, 89, 29-32.

11 Y. Watanabe, Plasma Phys. Controlled Fusion, 1997, 39, A59-A72.

12 K. Koga, Y. Matsuoka, K. Tanaka, M. Shiratani and Y. Watanabe, Appl. Phys. Lett., 2000, 77, 196-198.

13 S. J. Choi and M. J. Kushner, J. Appl. Phys., 1993, 74, 853-861.

14 C. Hollenstein, Plasma Phys. Controlled Fusion, 2000, 42, R93-R104.

15 A. Howling, C. Courteille, J. L. Dorier, L. Sansonnens and C. Hollenstein, Pure Appl. Chem., 1996, 68, 1017-1022.

16 Y. Zhao and D. G. Truhlar, J. Chem. Theory Comput., 2008, 4, 1849-1868.

17 B. J. Lynch, Y. Zhao and D. G. Truhlar, J. Phys. Chem. A, 2003, 107, 1384-1388.

18 R. Krishnan, J. S. Binkley, R. Seeger and J. Pople, J. Chem. Phys., 1980, 72, 650-654.

19 T. Clark, J. Chandrasekhar, G. W. Spitznagel and P. Schleyer, J. Comput. Chem., 1983, 4, 294-301.

20 M. J. Frisch, J. A. Pople and J. S. Binkley, J. Chem. Phys., 1984, 80, 3265-3269.

21 J. Zheng, Y. Zhao and D. G. Truhlar, J. Chem. Theory Comput., 2009, 5, 808-821.

22 V. I. Lebedev and L. Skorokhodov, Russian Acad. Sci. Dokl. Math., 1992, 45, 587-592.

23 M. J. Frisch, G. W. Trucks, H. B. Schlegel, G. E. Scuseria, M. A. Robb, J. R. Cheeseman, G. Scalmani, V. Barone, B. Mennucci, G. A. Petersson, H. Nakatsuji, M. Caricato, X. Li, H. P. Hratchian, A. F. Izmaylov, J. Bloino, G. Zheng, J. L. Sonnenberg, M. Hada, M. Ehara, K. Toyota, R. Fukuda, J. Hasegawa, M. Ishida, T. Nakajima, Y. Honda, O. Kitao, 
H. Nakai, T. Vreven, J. A. Montgomery, Jr., J. E. Peralta, F. Ogliaro, M. Bearpark, J. J. Heyd, E. Brothers, K. N. Kudin, V. N. Staroverov, R. Kobayashi, J. Normand, K. Raghavachari, A. Rendell, J. C. Burant, S. S. Iyengar, J. Tomasi, M. Cossi, N. Rega, J. M. Millam, M. Klene, J. E. Knox, J. B. Cross, V. Bakken, C. Adamo, J. Jaramillo, R. Gomperts, R. E. Stratmann, O. Yazyev, A. J. Austin, R. Cammi, C. Pomelli, J. Ochterski, R. L. Martin, K. Morokuma, V. G. Zakrzewski, G. A. Voth, P. Salvador, J. J. Dannenberg, S. Dapprich, A. D. Daniels, O. Farkas, J. B. Foresman, J. V. Ortiz, J. Cioslowski and D. J. Fox, Gaussian 09 (Revision D. 01), Gaussian, Inc., Wallingford, CT, 2009.

24 Y. Zhao, R. Peverati, K. Yang and D. G. Truhlar, $M N-G F M$ version 5.2 computer program module, University of Minnesota, Minneapolis, 2011.

25 A. V. Marenich, S. V. Jerome, C. J. Cramer and D. G. Truhalr, J. Chem. Theory Comput., 2012, 8, 527-541.

26 A. V. Marenich, C. J. Cramer and D. G. Truhalr, CM5PAC version 2013, University of Minnesota, Minneapolis, 2013.

27 F. L. Hirshfeld, Theor. Chim. Acta, 1977, 44, 129-138.

28 T. Yu, J. Zheng and D. G. Truhlar, Chem. Sci., 2011, 2, 2199-2213.

29 B. C. Garrett and D. G. Truhlar, J. Chem. Phys., 1979, 70, 1593-1598.

30 B. C. Garrett and D. G. Truhlar, Acc. Chem. Res., 1980, 13, 440-448.

31 D. G. Truhlar, A. D. Isaacson and B. C. Garrett, in Theory of Chemical Reaction Dynamics, ed. M. Baer, CRC Press, Boca Raton, 1985, pp. 65-137.

32 Y. P. Liu, G. C. Lynch, T. N. Truong, D.-H. Lu and D. G. Truhlar, J. Am. Chem. Soc., 1993, 115, 2408-2415.
33 J. Zheng and D. G. Truhlar, J. Chem. Theory Comput., 2013, 9, 1356-1367.

34 J. Zheng, S. L. Mielke, K. L. Clarkson and D. G. Truhlar, MSTor computer program, version 2011, University of Minnesota, Minneapolis, MN, 2011.

35 K. A. Nguyen, C. F. Jackels and D. G. Truhlar, J. Chem. Phys., 1996, 104, 6491-6496.

36 C. F. Jackels, Z. Gu and D. G. Truhlar, J. Chem. Phys., 1995, 102, 3188-3201.

37 I. M. Alecu, J. Zheng, Y. Zhao and D. G. Truhlar, J. Chem. Theory Comput., 2010, 6, 2872-2887.

38 J. Zheng, S. Zhang, B. J. Lynch, J. C. Corchado, Y.-Y. Chuang, P. L. Fast, W.-P. Hu, Y.-P. Liu, G. C. Lynch, K. A. Nguyen, C. F. Jackels, A. F. Ramos, B. A. Ellingson, V. S. Melissas, J. Vill_a, I. Rossi, E. L. Coitino, J. Pu, T. V. Albu, R. Steckler, B. C. Garrett, A. D. Isaacson and D. G. Truhlar, POLYRATE, version 2010-A, University of Minnesota, Minneapolis, 2010.

39 J. Zheng, S. Zhang, J. C. Corchado, Y. Y. Chuang, E. L. Coitiño, B. A. Ellingson and D. G. Truhlar, GAUSSRATE, version 2009-A, University of Minnesota, Minneapolis, 2010.

40 P. Seal and D. G. Truhlar, J. Am. Chem. Soc., 2014, 136, 2786-2799.

41 J. Zheng and D. G. Truhlar, Phys. Chem. Chem. Phys., 2010, 12, 7782-7793.

42 J. Zheng, P. Seal and D. G. Truhlar, Chem. Sci., 2013, 4, 200-212.

43 D. G. Truhlar, J. Chem. Educ., 1978, 55, 309-311.

44 A. Fernández-Ramos, J. A. Miller, S. J. Klippenstein and D. G. Truhlar, Chem. Rev., 2006, 106, 4518-4584.

45 S. J. Klippenstein, V. Pande and D. G. Truhlar, J. Am. Chem. Soc., 2014, 136, 528-546. 